\title{
Flash Rips in Voodoo Land
}

\section{Bruno Castelle ${ }^{1,2^{*}}$ and Tim Scott ${ }^{3}$}

\begin{abstract}
${ }^{1}$ CNRS, UMR 5805 EPOC, Allée Geoffroy Saint-Hilaire, 33615 Pessac, France
${ }^{2}$ Université de Bordeaux, UMR 5805 EPOC, Allée Geoffroy Saint-Hilaire, 33615 Pessac, France

${ }^{3}$ School of Marine Science and Engineering, University of Plymouth, Plymouth PL4 8AA, UK

The field experiment at Grand Popo (Benin, West Africa; Figure 1) led by Dr. Rafael Almar (Laboratory for Studies in Geophysics and Spatial Oceanography, LEGOS) on February 10-19, 2014, was supposed to both learn and build from the past mistakes made during the field experiment in 2013, exactly one year before at the same site. Grand Popo is located at the western end of Benin, near the Togo border and is located only approximately $80 \mathrm{~km}$ from the capital Cotonou. Nevertheless, 4 hours of grueling driving on epic roads are needed to reach the quiet coastal village of Grand Popo and this gorgeous remote beach (Figure 1).
\end{abstract}
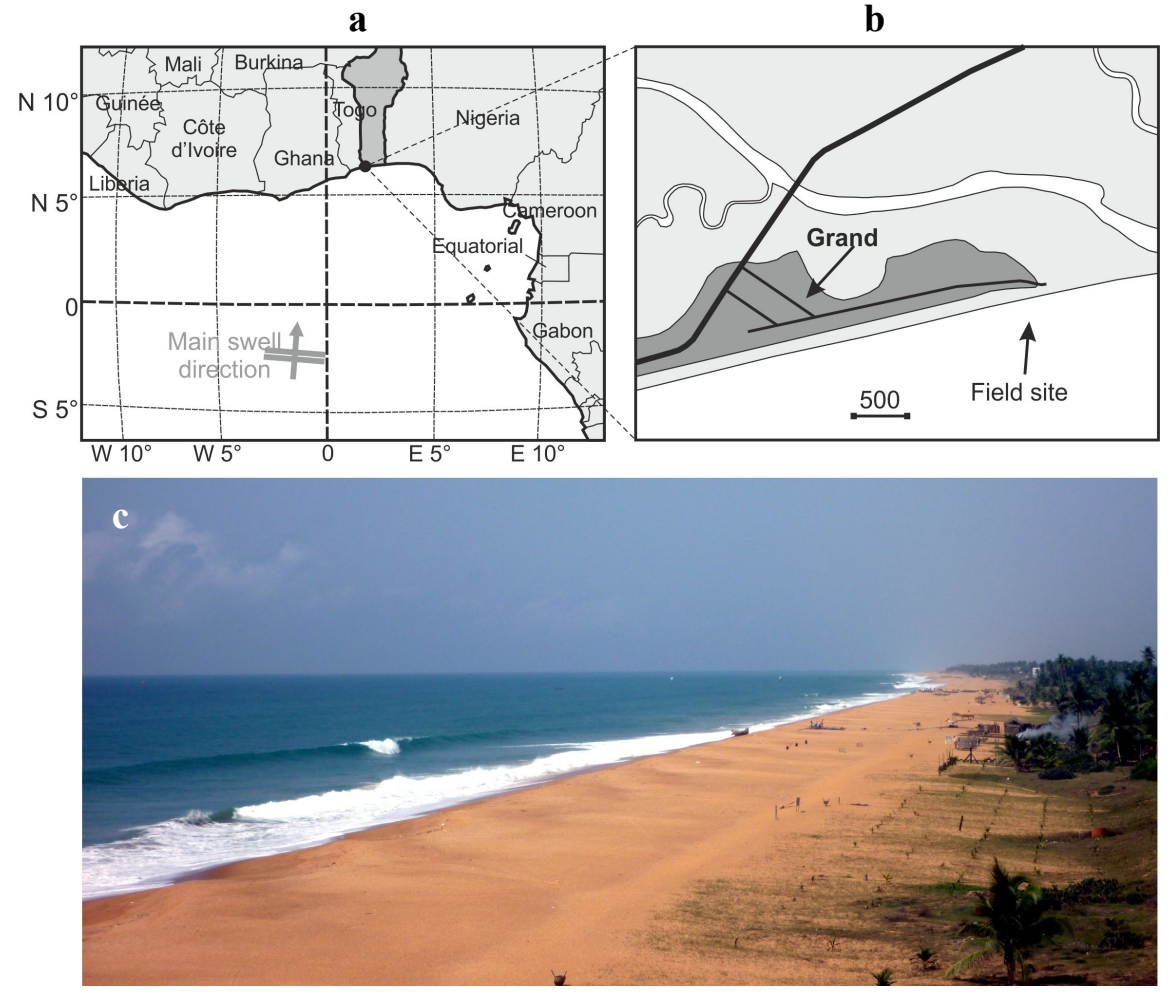

Figure 1. (a,b) Location map of Grand Popo, Benin, West Africa, adapted from Castelle et al. (2014). (c) View of the beach from the Beninese army camp tower. (Photo: B. Castelle.)

During the 2013 experiment (Almar et al., 2014), a few French (Université de Bordeaux, Université Aix-Marseille) and African (Université Abomey Calavi, University of Ghana) researchers, undergraduate students, and the odd interested fisherman, gathered at Grand Popo to perform the first West African nearshore experiment at this low-tide terraced beach. It was clear from satellite images that the shoreline and nearshore morphology barely changes at Grand Popo, so this site was not selected for an experiment hoping to address dramatic morphological changes.

DOI: 10.2112/JCR-SI101-066.1

*Corresponding author: bruno.castelle@u-bordeaux.fr

${ }^{\circ}$ Coastal Education and Research Foundation, Inc. 2020 
However, it was also clear that Grand Popo exhibits nicely defined beach cusp systems and is exposed to energetic groundswell generated in the South Atlantic Ocean, which could potentially drive strong longshore currents. Even more glaringly obvious on the first day arriving at the beach were the superb flash rips flushing the surf zone. In fact, before arriving here in 2013, we did not know anything about the prevailing nearshore circulation. Just in case, I had brought a few GPS devices and water proof bags to at least have a rough measure of the surface longshore current, to be combined with near-bottom Eulerian flow data. The GPS devices would be of great use to measure the Lagrangian flow of flash rips at this site. All we needed to do was to spend hours in the $30^{\circ} \mathrm{C}$ water drifting in the surf.

In the end, the 2013 experiment was a true crash test. For instance, the aim of the first day was to mount pressure sensors on the terrace at dead low tide (spring tide range of $1.6 \mathrm{~m}$ ). However, at the supposed low tide we found ourselves fighting a shorebreak (Figure 2a), barely able to hammer the poles on which the sensors were mounted. There was something wrong! At the end of the day, we checked the tide charts again - and someone had flipped the tide time series - it was clearly high tide, not low tide! The next morning, all the sensors had disappeared and most of the (rather thin) sticks were broken - of course. Some argued that the sensors were all mysteriously stolen and went to the head of the village to ask for local people to bring back the sensors, while others went as far as to rely on voodoo practices (Figure 2b). Unsurprisingly this did not help recover the sensors, because, and despite our earlier warning, all the mounting poles were made of thin wooden sticks and therefore absolutely not suitable to support sensors, particularly in the surf.

One learns from mistakes, especially during their first surf zone experiment. It was clear that having a decent bathymetric survey was critical to understand what was going on at this site, but going offshore from the beach was hazardous, with no ports for miles, and a consistent heavy shorebreak. So after a quick trip to the village we agreed to use a local fishing boat (well canoe really!) and the survey instruments were attached. Unsurprisingly, after waiting for the calmest of days, when we put the boat in the water the biggest set of the day came through and wrecked it in the shorebreak (Figure 2c,d). Luckily there was no severe injury, just a fright. We eventually had a rough and incomplete bathymetric survey, but it was well offshore, without any data along the entire terrace morphology. In the end, there was no nearshore Eulerian flow and wave measurements and no nearshore bathymetry during that 2013 experiment. Without any bathymetry depicting the terrace morphology, it was not possible to run a numerical model to further explain nearshore hydrodynamics and morphological changes in this region. So the experiment was put down as a learning experience.

During the course of the field experiment, it also did not take long for the French team to be struck down by the damp heat, and also the lack of food. We all lost a lot of weight in only 10 days. In fact, it was not really the lack of, but the type of food that was the problem, as during the day we had to eat Beninese Navy barrack meals. Believe it or not, the French can get even grumpier when it comes to food.

Amid the failures, there were a few successes, which were a source for hope, including the installation of a permanent video system (Almar et al., 2014), the monitoring of the beach cusp evolution (Sénéchal et al., 2014) and some fresh insight into flash rip dynamics in West Africa (Castelle et al., 2014). We documented high-energy $(0.2-0.8 \mathrm{~m} / \mathrm{s})$ flash rips, with activity maximized at low tide, which tended to migrate downdrift with a time-span of about 2-5 minutes, under relatively weak longshore currents $(0.2-0.55 \mathrm{~m} / \mathrm{s})$. However, this flash rip study was incomplete and frustrating: human drifters were getting pounded for hours by plunging breakers and sometimes washed ashore in the shore-break. We would only be occasionally expelled offshore by a pulsing 


\section{Castelle and Scott}

flash rip, which was always a source of tremendous pleasure, but we often only had 2-3 people who were comfortable in the surf who could be used as human drifters. All the effort was not that rewarding in the end given the little amount of data collected (Figure 3).

However, we needed to come back, with decent mounting rigs, with reliable tide data, and with a rip current scientist bringing state-of-the-art surf zone drifters to collect much more Lagrangian data. Field experiments are always better with guys who are easy going, talented and with similar research interests, who do not take themselves too seriously, and of course who are dedicated after-work cold beer lovers. Given it was a French field experiment in a francophone African country in a remote place, it was a necessary requirement for this rip scientist to be a fluent French speaker. Tim Scott from Plymouth University emerged as the obvious person to invite even though he doesn't speak French. We had already done surf zone experiments together in Truc Vert, France in 2008 and Perranporth, UK in 2011, and had met a few times at conferences and had a lot in common. Like me, he was a bit tired with rips flowing in well-defined channels, and a tropical flash rip break in the middle of the UK winter was appealing. We were more than ready, we knew what to do, we knew what not to do. This time we would collect fantastic wave and nearshore bathymetry data, Eulerian measurements in the surf zone with sensors mounted on unbreakable heavy metal thick poles that we would implement during low tide (the true low tide of course). We would subsequently come back home tanned and super fit despite the beers, with a unique dataset to play with!
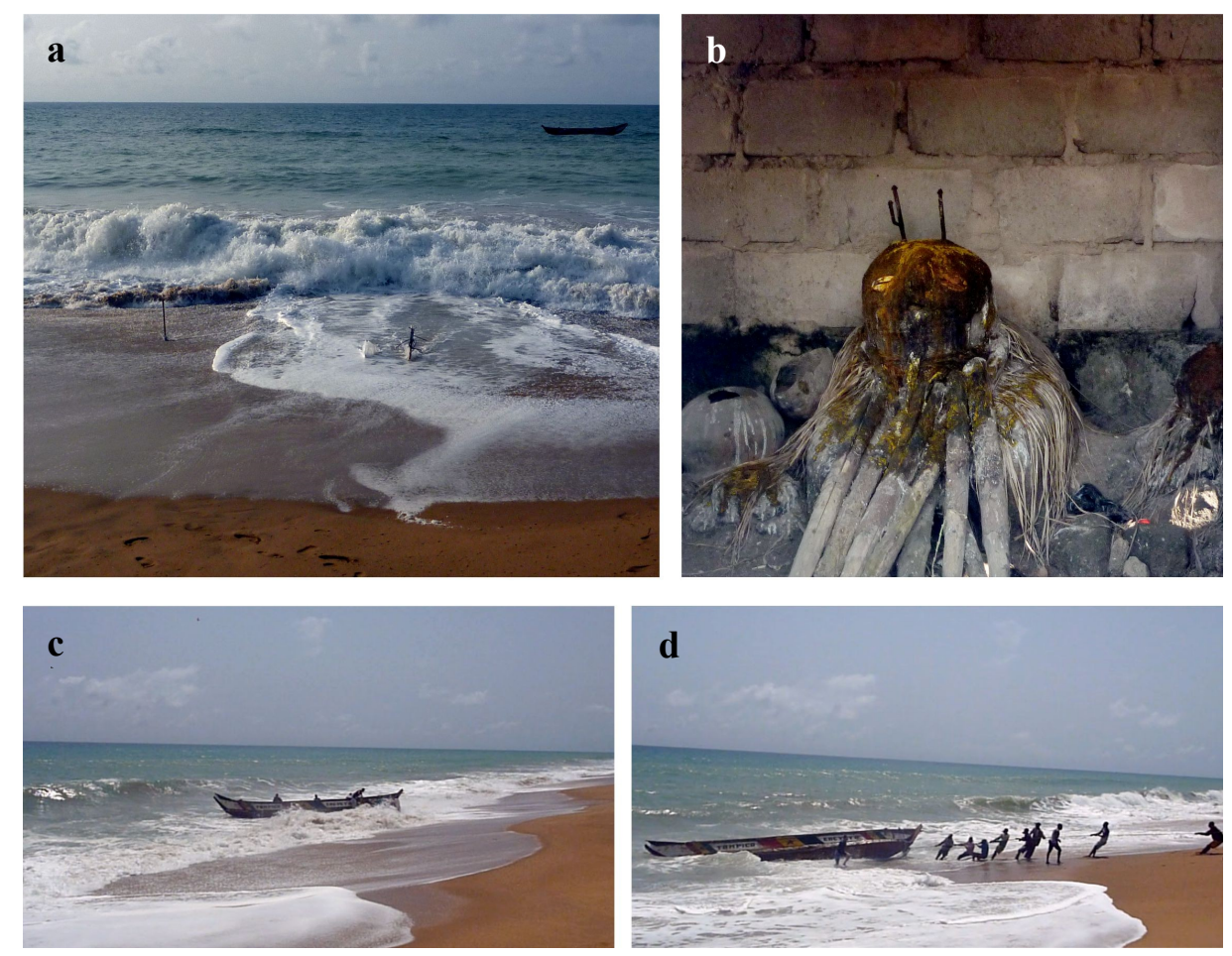

Figure 2. (a) Nope, this is definitely not the offshore extent of the low tide terrace at low tide; it rather looks like a nice little high tide shore-break. (b) The voodoo that could have helped recovering the sensors. (c,d) How not to launch a traditional fishing boat from the beach in order to run an offshore bathymetric survey. In the end, the boat was full of water and unable to float. (Photos: B. Castelle.)

So in March 2014, we returned to Grand Popo and stayed at the same guest house, but with much improved food (much to Tim's horror, who wondered what on earth they ate in 2013). It was still not a Michelin star restaurant though, which was enough cause for the French to still complain. It was still the same beach, used for the same purpose by the locals: fishing playground and toilet. Indeed, 
locals come to the beach to poop in peace, and doing that just a few meters from Nadia Sénéchal walking with a DGPS, did not seem to bother them. Importantly, we had our daily spare time at night at a nearby small empty beach bar long been run by a French woman with strong local network. Our 10 days there may have been equivalent to a quarter annual turnover for her bar, so she took care of us, for instance inviting musicians while we were sharing well deserved beers and (rarer) nonalcoholic cocktails. This is also when ideas and scientific discussions between colleagues and students were maximized. This was the only time of the day that we felt a bit of freshness thanks to a sea breeze cooling the air to $28^{\circ} \mathrm{C}$ in the evening! The damp heat $\left(>30^{\circ} \mathrm{C}\right)$ and burning sun were the same as in 2013, the kind of heat that makes every little effort a challenge. After two days Tim was as red as a transgenic tomato. But for sure, overall food and drink conditions were much better than in 2013.

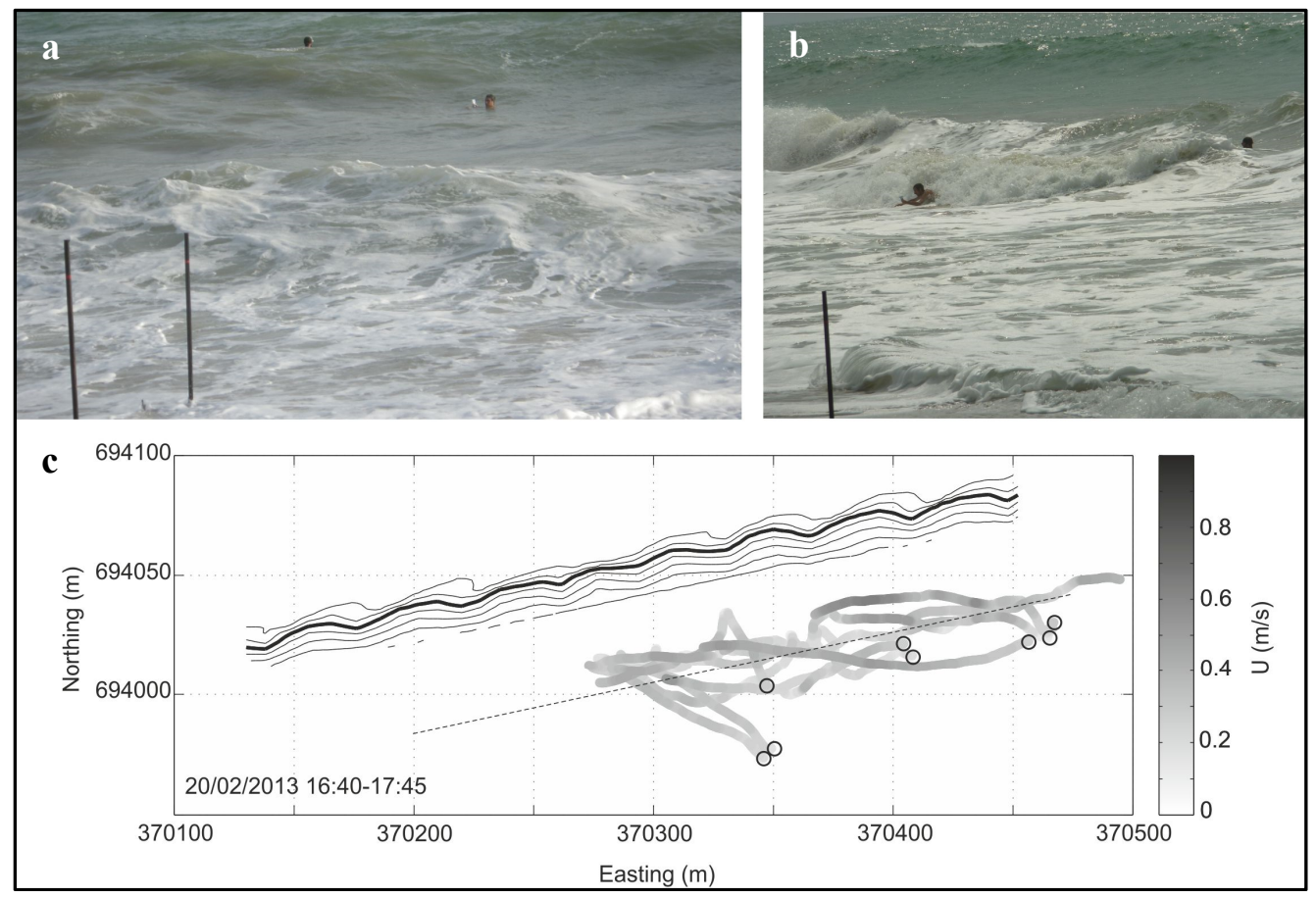

Figure 3. (a) Being caught in a flash rip as a human drifter was a tremendous pleasure as it meant good data and a moment's relief before being pounded again in the narrow surf zone. (b) It was also a reason to eventually have a bit of fun bodysurfing to come back ashore. (c) Example of a day with a lot of flash rips and resulting surf zone exits with human drifter tracks with black circles indicating the final position of drifter exits. The grey color shows flow velocity in $\mathrm{m} / \mathrm{s}$ and the alongshore dotted black line shows the arbitrary the surf zone edge, while the solid black lines are isocontours of the topography highlighting the presence of well-developed beach cusps. (Adapted from Castelle et al., 2014.)

But let's get back to the flash rips. They were still there, although during the two first days, when we did all drifter tests, the nearshore circulation was dominated by a strong longshore current, which did not alter Tim's legendary calm. Although we now had GPS drifters, we had to admit that we still needed a large team of people in the water to be able to quickly retrieve drifters transported offshore, or when they exited our study domain downdrift, always at different times (Figure 4a-c). In addition, it was so hot that walking along the beach downdrift to follow the drifters was grueling. It was cooler to be in the $30^{\circ} \mathrm{C}$ water, and then only walk to re-seed the drifters in the updrift part of our study domain a couple of hundred meters updrift. Contrary to 2014, the GPS devices were on the drifters, and we were then free to enjoy bodysurfing while the drifters were moving with ambient currents, which was a lot of fun. 


\section{Castelle and Scott}

We once again collected some nice Lagrangian flash rip data, although not as many as we could have given we were still a limited number of people in the surf. We were typically three to four people in the water for four drifters during six days of measurements (Figure 4a-c). We also performed some more or less successful dye release experiments (Figure 4d,e) that did not add much to our research, except to qualitatively confirm visually what we felt in the water. Combining this new data we managed to improve our understanding of flash rip dynamics in this region of the world (Scott et al., 2018). In particular, we provided further quantitative insights into the role of specific wave/tide forcing characteristics on flash rip activity, specifically the importance of reduced directional spreading and tidal level in controlling increases in offshore extent of flash rip currents. Given the observed ubiquity of significant hazardous transient flash rip activity and identification of key behavioral controls we anticipated that our work can provide a foundation for any future development of rip hazard prediction tools and effective lifeguarding in West Africa.

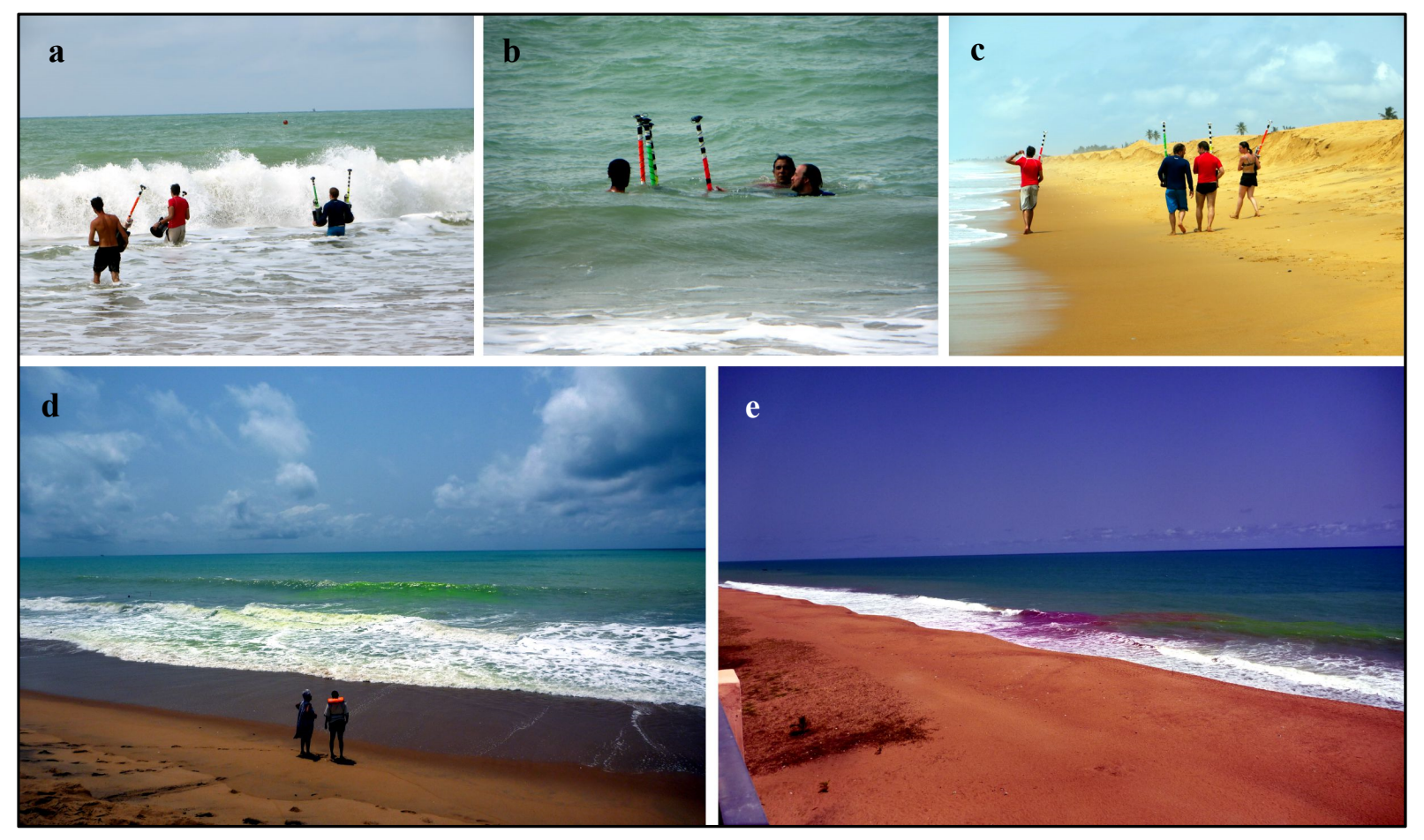

Figure 4. Top panels show the typical experience of Grand Popo drifter experiments with (a) walking to reach the surf zone limit where (b) drifters were seeded before being subsequently retrieved at the downdrift end of the study domain and (c) further transported updrift by walking. (d-e) Dye release experiments highlighting the presence of occasional flash rips. (Photos: B. Castelle.)

Given our experience with the 2013 experiment we knew that particular attention had to be paid to measuring the terrace topography and nearshore bathymetry. We unfortunately had similar issues: it was not possible to survey the nearshore bathymetry in less than 3-4 m depth with a local canoe. We did try to collect decent topography of the terrace at dead low tide during low waves (Figure 5), but only a little section was able to be surveyed, at which point, Tim's frustration at the lack of bathymetry got the better of him and he tried to swim-survey in a 4-foot shore-break with the DGPS equipment. This methodology is not recommended. 


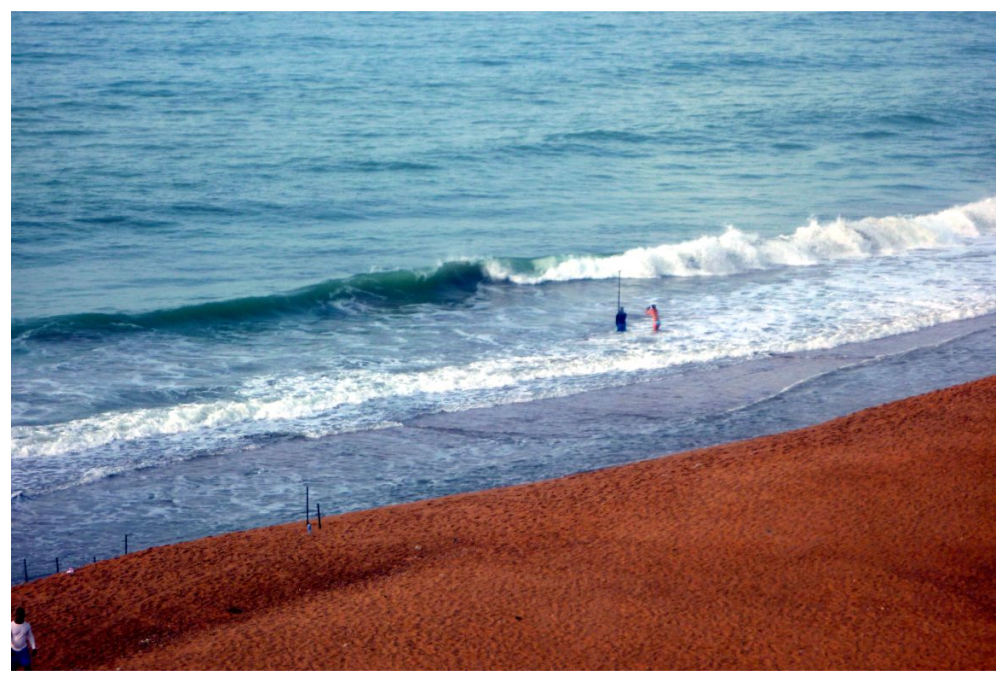

Figure 5. Tim Scott trying to survey the terrace morphology at low tide with a $10 \mathrm{ft}$ pole approaching the breaking point, with the help of Nadia Sénéchal holding the data collector. (Photo: B. Castelle.)

Some colleagues brought a heavy, state-of-the-art, drone to collect aerial views of the study area, and potentially to perform depth inversion. However, it turns out that high heat reduces battery life and the drone soon fell out of the sky, crashing only a few meters from Nadia Sénéchal. Although the mounting and further collecting of the offshore ADCP measuring directional wave conditions went well, back in France we realized that most of the wave measurements were flawed, in fact the time series of significant wave height had not much to do what we had observed. It took some time for the time series to be somewhat corrected into some more or less good-looking data.

Once again, the conditions were difficult for everyone involved, except for the field experiment leader Rafael Almar. Those who know Rafael think he's a machine: he is skinny, but eats incredible quantities of any food (he was the only one not losing weight in 2013), is always happy and has the ability to show no sign of stress even if everything around is falling apart. He is a bit of a magician too as he can retrieve bathymetric data where no measurements exist. Coming back to Europe was another story with (like always), many hours spent with customs at the airport because of our equipment. In the end, we all went back home tanned and fit, but again tired and unsure about what to do with the data.

Thanks to the fantastic support of an army camp (Figure 6a) and the energy of Rafael Almar, this field experiment provided us a taste of what the first experiments from the good old days in the US, Canada and Australia must have been like: without decent safety procedures; when there were not many rules to be hassled with; and where resourcefulness was needed to make things happen. It is tough experiments like these that forge ties between scientists (Figure 6b). This 2014 Grand Popo experiment was for instance the initiation a long running collaboration between me and Tim on rip currents (e.g., Castelle et al., 2016; McCarroll et al., 2018), but also beach response and recovery from storms (e.g., Dodet et al., 2019) and wave climate variability (e.g., Castelle et al., 2017). Such field experiments are also sources of discussion, new ideas and a lot of fun with all colleagues which are maximized in such remote and isolated locations. In Grand Popo, it was also the occasion to meet a number of talented African students, some of them would become our Ph.D. students (Donatus Angnurreng, Grégoire Abessolo Ondoa). It was also the occasion to enjoy the Beninese hospitality and to immerse in an amazing and unique culture in the birthplace of voodoo (Figure 6c). Most of the time, these are not the experiments that you do great science, but they are definitely a milestone in a research career. We think we will come back in Grand Popo one day to get more insight into these 


\section{Castelle and Scott}

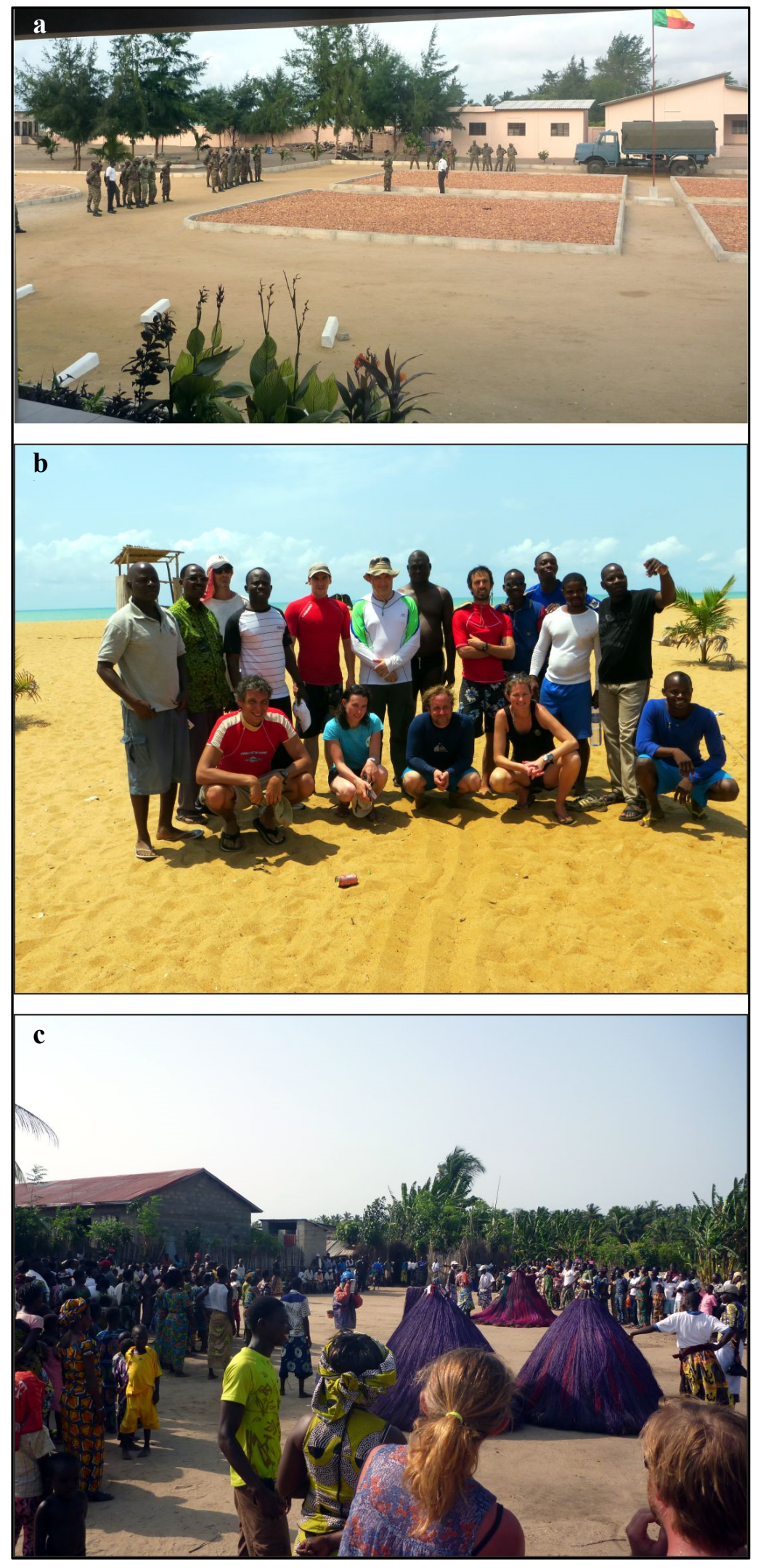

Figure 6. (a) Army camp where we had lunch/dinner and in front of which our study zone was located. (b) Group photo of the March 2014 experiment. (c) Cultic voodoo feast. (Photos: B. Castelle.) 
flash rips, with decent Eulerian measurements arrays, accurate nearshore bathymetries across the entire terrace, reliable offshore wave forcing and plenty of drifters. We know what to do. We know what not to do.

\section{ACKNOWLEDGEMENTS}

We thank Rafael Almar (LEGOS) for leading these two pioneering nearshore field experiments in West Africa and all the colleagues involved in the two field experiments, particularly France Floc'h and Matthieu Dorel who helped with the drifter measurements. We also thank the naval services of Benin at Grand Popo for their logistic support during the field experiment. We thank Rob Brander for the in-depth editing of our story.

\section{LITERATURE CITED}

Almar, R.; Hounkonnou, N.; Anthony, E.; Castelle, B.; Senechal, N.; Laibi, R.; Mensah-Senoo, T.; Degbe, G.; Quenum, M.; Dorel, M.; Chuchla, R.; Lefebvre, J-P; du Penhoat, Y.; Laryea, W.S.; Zodehougan, G.; Sohou, Z.; Appeaning Addo, K., and Kestenare, E., 2014. The Grand Popo beach 2013 experiment, Benin, West Africa: From short timescale processes to their integrated impact over long-term coastal evolution. In: Green, A.N. and Cooper, J.A.G. (eds.), Proceedings of the 13th International Coastal Symposium (Durban, South Africa). Journal of Coastal Research, Special Issue 70, pp. 651-656.

Castelle, B.; Almar, R.; Dorel, M.; Lefebvre, J.P.; Senechal, N.; Anthony, E.J.; Laibi, R.; Chuchla, R., and du Penhoat, Y., 2014. Rip currents and circulation on a high-energy low-tide-terraced beach (Grand Popo, Benin, West Africa). In: Green, A.N. and Cooper, J.A.G. (eds.), Proceedings of the 13th International Coastal Symposium (Durban, South Africa). Journal of Coastal Research, Special Issue No. 70, pp. 633-638.

Castelle, B.; Dodet, G.; Masselink, G., and Scott, T., 2017. A new climate index controlling winter wave activity along the Atlantic coast of Europe: The West Europe Pressure Anomaly. Geophysical Research Letters, 44(3), 1384-1392.

Castelle, B.; Scott, T.; Brander, R.W., and McCarroll, R.J., 2016. Rip current types, circulation and hazard. Earth-Science Reviews, 163, 1-21.

Dodet, G.; Castelle, B.; Masselink, G.; Scott, T.; Davidson, M.; Floc'h, F.; Jackson, D., and Suanez, S., 2019. Beach recovery from extreme storm activity during the 2013/14 winter along the Atlantic coast of Europe. Earth Surface Processes and Landforms, 44(1), 393-401.

McCarroll, R.J.; Brander, R.W.; Scott, T., and Castelle, B., 2018. Bathymetric controls on rotational surfzone currents. Journal of Geophysical Research: Earth Surface, 123, 1295-1316.

Scott, T.; Castelle, B.; Almar, R.; Senechal, N.; Floc'h, F., and Detandt, G., 2018. Controls on flash rip current hazard on low-tide terraced tropical beaches in West Africa. In: Almar, R.; Almeida, L.P.; Trung Viet, N., and Sall, M. (eds.), Tropical Coastal and Estuarine Dynamics. Journal of Coastal Research, Special Issue No. 81, pp. 92-99.

Sénéchal, N.; Laibi, R.A.; Almar, R.; Castelle, B.; Biausque, M.; Lefebvre, J-P.; Anthony, E.; Dorel, M.; Chuchla, R.; Hounkonnou, M.H., and Du Penhoat, Y., 2014. Observation of the destruction of a beach cusp system in presence of a double coupled cusp system: The example of Grand Popo Benin. In: Green, A.N. and Cooper, J.A.G. (eds.), Proceedings of the 13th International Coastal Symposium (Durban, South Africa). Journal of Coastal Research, Special Issue No. 70, pp. 669674. 